Check for updates

The BMJ

Cite this as: $B M J 2020 ; 371: \mathrm{m} 4733$ http://dx.doi.org/10.1136/bmj.m4733 Published: 03 December 2020

\section{Some care home residents may have died because of blanket DNR orders, says regulator}

\author{
Clare Dyer
}

Some care home residents were wrongly subjected to decisions ruling out attempts at cardiopulmonary resuscitation (CPR) in the early stages of the covid-19 pandemic, leading to potentially avoidable deaths, the Care Quality Commission (CQC) has concluded. ${ }^{1}$

Advance instructions not to attempt CPR should a patient's heart or breathing stop in future should be discussed with patients, if they have the capacity to consent, or with their family, and made on an individual basis. But amid fears that hospitals would be overwhelmed with covid-19 patients, some care homes were given blanket DNACPR (do not attempt cardiopulmonary resuscitation) notices. An Amnesty International report in October, which called for a full public inquiry, found inappropriate or unlawful use of DNACPRs by GPs, clinical commissioning groups, hospitals, and care homes. ${ }^{2}$

In an interim report, the CQC found that "providers sometimes conflated decisions about DNACPR with decisions about whether to admit people to hospital or provide covid-19 treatment.” There were examples where ambulances were not called straight away or there was a delay in calling doctors.

The Department for Health and Social Care for England commissioned the CQC to carry out the review, prompted by concerns about the blanket application of DNACPR decisions during the pandemic. "It is unacceptable for clinical decisions-which could dictate whether someone gets the right care when they need it most-to be applied in a blanket approach to any group of people," said Rosie Benneyworth, chief inspector of primary medical services and integrated care at the CQC. "There is very real concern that decisions were made which not only overlooked the wishes of the people they affected but may have been made without their knowledge or consent." Some people reported that they were unaware that a relative had a DNACPR decision until the relative was quite unwell.

The CQC will carry out a full review into the use of DNACPRs as part of advance care planning during the pandemic, reporting in February 2021, to "inform national learning and improvement, and support good practice development." Some stakeholders told the regulator that poor practice around DNACPRs was "a longstanding problem that the pandemic has exposed and exacerbated.”

The interim report found no evidence to suggest that the use of unacceptable and inappropriate DNACPRs had continued as a widespread practice but warned that it was possible that some remained in place. "We expect all providers and local systems to ensure that any discussions about DNACPRs happen as part of person centred advance care planning, and in accordance with legal requirements," the report said.

1 Care Quality Commission. Review of do not attempt cardiopulmonary resuscitation decisions during the covid-19 pandemic. Interim report. November 2020 www.cqc.org.uk/publications/themed-work/review-do-not-attempt-cardiopulmonary-resuscitation-decisions-during-covid.

2 Amnesty International. As if expendable: the UK government's failure to protect older people in care homes during the covid-19 pandemic. 4 October 2020. www.amnesty.org.uk/files/2020-10/Care\%20Homes\%20Report.pdf?kd5Z8eWzj8Q6ryzHkcaUnxfCtqe5Ddg6=. 